\title{
Long-term catheterization: current approaches in the diagnosis and treatment of port-related infections
}

This article was published in the following Dove Press journal:

Infection and Drug Resistance

18 February 2014

Number of times this article has been viewed

\author{
Cesar Bustos' \\ Aitziber Aguinaga' \\ Francisco Carmona-Torre ${ }^{2}$ \\ Jose Luis Del Pozol,3 \\ 'Department of Clinical Microbiology, \\ 2Department of Internal Medicine, \\ ${ }^{3}$ Division of Infectious Diseases, \\ Clinica Universidad de Navarra, \\ Pamplona, Spain
}

\begin{abstract}
Since the first description in 1982, totally implanted venous access ports have progressively improved patients' quality of life and medical assistance when a medical condition requires the use of long-term venous access. Currently, they are part of the standard medical care for oncohematologic patients. However, apart from mechanical and thrombotic complications, there are also complications associated with biofilm development inside the catheters. These biofilms increase the cost of medical assistance and extend hospitalization. The most frequently involved micro-organisms in these infections are gram-positive cocci. Many efforts have been made to understand biofilm formation within the lumen catheters, and to resolve catheterrelated infection once it has been established. Apart from systemic antibiotic treatment, the use of local catheter treatment (ie, antibiotic lock technique) is widely employed. Many different antimicrobial options have been tested, with different outcomes, in clinical and in in vitro assays. The stability of antibiotic concentration in the lock solution once instilled inside the catheter lumen remains unresolved. To prevent infection, it is mandatory to perform hand hygiene before catheter insertion and manipulation, and to disinfect catheter hubs, connectors, and injection ports before accessing the catheter. At present, there are still unresolved questions regarding the best antimicrobial agent for catheter-related bloodstream infection treatment and the duration of concentration stability of the antibiotic solution within the lumen of the port.
\end{abstract}

Keywords: catheter-related infection, bacteremia, biofilm

\section{Introduction}

The use of totally implanted venous access devices has become a routine procedure since it was first described in 1982, when the use of a novel system consisting of a silicone rubber catheter connected to a subcutaneously placed molded plastic injection port for administration of intra-arterial chemotherapy was reported. ${ }^{1}$ Ports have progressively improved patients' quality of life and medical assistance when a medical condition requires the use of a long-term venous access for administration of blood products, fluids, chemotherapy, antibiotics, or total parenteral nutrition. Ports are also useful for blood sampling procedures. Currently, they are part of the standard medical care for oncohematologic patients. However, infection is a major problem when it develops.

As occurs with other medical devices, infections are associated with biofilm development. Measures taken to reduce the occurrence of catheter-related infections (CRI) are not always enough to avoid biofilm generation. In some cases, infections are aggressive or may turn persistent, threatening the patient's life. These situations often require catheter removal and prolonged systemic antibiotic treatment, which can
Correspondence: Jose Luis Del Pozo Clinica Universidad de Navarra, Av de Pío XII, 36, 31008 , Pamplona, Navarra, Spain Email jdelpozo@unav.es 
deteriorate clinical condition of the patient and complicate medical assistance.

\section{Long-term catheters}

Central venous catheters (CVC) may be necessary for temporary or long-term use. Long-term catheters may be partially or totally indwelling, and can be placed through an open surgical or percutaneous approach. A venous catheter indwelling for more than 14 days is considered a long-term venous catheter. ${ }^{2}$

There are two types of long-term central venous catheters: cuffed or tunneled catheters, and catheters that end in a subcutaneous reservoir. Ports are composed of two parts: a central injection chamber, called the reservoir, which is made of titanium steel and has a self-sealing silicone rubber membrane; and a silicone rubber outlet catheter, to which the reservoir is connected. The standard implantation technique places the catheter in the right infraclavicular space via skin incision. ${ }^{1,3}$ Reservoirs are located in a pocket created under the skin surface and fixed to the underlying muscle fascia. The outlet catheter leads through a subcutaneous tunnel into a central vein. The catheter tip is left near the junction of the superior vena cava with the right atrium. The access to the silicone septum is made using a Huber point needle that is placed through a percutaneous insertion. This needle preserves the integrity of the septum. Ports need only a monthly flush of heparin to avoid thrombotic complications.

\section{Prevalence of venous catheter-related infections}

In spite of the precautionary measures taken, such as skin cleaning using a $70 \%$ alcohol or $0.5 \%$ chlorhexidine solution, it is estimated that the number of bloodstream infections (BSI) related to intravascular devices (IVD) range between 250,000 and 500,000 per year in the US. ${ }^{4}$

Data reported from the National Healthcare Safety Network indicate that rates of central line-associated BSI in long-term acute care hospitals are 1.25 events per 1,000 device days (range, 0.0-5.96), ${ }^{5}$ but the trend of catheterrelated bloodstream infection (CRBSI) decreased during the past decade, as was pointed out in a 2010 report of infection control in intensive care units. ${ }^{5}$

Ports are preferred for pediatric and oncohematologic patients because of their simplicity when used by qualified health care professionals. However, the rate of port infection in this patient group ranges from 0.016 to $0.25 / 1,000$ IVD days. ${ }^{3,4,6}$

\section{Pathogenesis: bacterial biofilm development}

As well as other infections related to almost every temporary or permanent medical implant, such as orthopedic prosthesis and cardiac and neurological devices, ${ }^{8}$ venous device infections are associated with biofilm development on the surface of the foreign body. Most of the infections originate from the skin microbiota surrounding the insertion site of the catheter. Micro-organisms reach the subcutaneous catheter tract at the moment of venous catheter implantation. This event is often related to external colonization of short-term catheters. ${ }^{2,9}$ For internal colonization of the catheter, the sources of microorganisms are the bloodstream, when transient bacteremia occurs, and catheter hubs' handling. Catheter manipulation is implicated with intraluminal colonization of long-term catheters. ${ }^{10,11}$ Repeated access to ports often leads to formation of intraluminal biofilm. ${ }^{4}$ It has been estimated that biofilms are associated with more than $70 \%$ of nosocomial infections, and that the treatment of these biofilm-related infections costs more than a billion dollars annually. ${ }^{12}$

The first descriptions of bacterial biofilms pertained to flowing-water systems, but it not was until the early 1980s when characterization of the bacterial glycocalyx and its inherent ability to form adherent microcolonies through cellular adhesion became relevant in the pathogenesis of infectious diseases. Since then, clinical reports have focused more frequently on infectious processes associated with medical device-associated biofilms.

The interaction between micro-organisms and synthetic material creates a complex structure known as biofilm; however, it is difficult to provide a unique definition due to the wide range of bacterial and host substances involved in the biofilm generation process. The first step in biofilm development is the attachment of bacterial cells to an artificial or native surface. Micro-organisms will form a community that will encase itself in a self-produced polymeric matrix. ${ }^{12,13}$ The physiological changes experienced by bacterial cells during transition from planktonic to attached state are complex. During this process, many different phenotypes of the same organism with distinct proteins expression can be characterized. ${ }^{14}$ Attached bacteria begin to form microcolonies and secrete a polymeric matrix. This matrix is a hydrated polyanionic complex of exopolysaccharides of bacterial origin, but can also be formed by proteins and DNA. As the polymeric matrix grow and matures, it builds a sophisticated system of water channels resembling a circulatory system for biofilm support. The fluid flow through the water channels is responsible for 
oxygenation, nourishment, hydration, removal of metabolic waste products, and communication between bacterial cells (quorum sensing); but this flow is not uniform, providing different cellular microenvironments. Therefore, oxygen diffusion at the center of cellular microcolonies is limited ${ }^{13}$ (Figure 1).

The composition and metabolism of biofilms may vary significantly depending on the involved micro-organism, the stage of maturity of bacterial cells, and the local and immune conditions of the host. This leads to multiple biofilm phenotypes, even among different species.

The generation process of biofilm may start only a few hours after venous device access has been placed; however, clinical features related to a CVC infection may not be apparent until days or weeks after a port has been used for medical care. As biofilm matures on the internal surface of a venous catheter, new bacterial populations are released to the bloodstream, either by single releasing cells or by biofilm particles' detachment. This process allows the micro-organisms to maintain an infection and reach new tissue surfaces, where they can generate new infectious processes.

\section{Biofilm-related issues}

Micro-organisms obtained from biofilm sessile cells from removed ports have the same minimal inhibitory concentration (MIC) as the planktonic form of the bacterial cells obtained from positive blood cultures drawn when ports were placed. ${ }^{15}$ This finding confirms the protection granted to bacterial cells growing in biofilms, even when antibiotics reach concentrations 1,000 times over that needed to kill planktonic cells in the bloodstream. ${ }^{15,16}$

Biofilms are resistant to the immune system. Therefore, complete clearance of biofilm is not possible by only the host immune system. Different mechanisms may be involved in giving the biofilm this kind of natural immunity, such as the inability of phagocyte cells to kill biofilm micro-organisms due to the poor penetration of reactive oxygen species into the biofilm. ${ }^{8}$

Biofilms are also resistant to antibiotic activity. Many factors are involved in this resistance, such as poor antibiotic penetration into the biofilm depths and the polymeric matrix of the biofilm structure. Both act at the same time as a barrier that might physically reduce antibiotic penetration and adsorb antimicrobials agents, reducing the drug available to interact with biofilm bacteria. ${ }^{12}$ Other factors associated with antimicrobial resistance are directly related to the organisms growing into the biofilm, and their microenvironment and metabolic state. ${ }^{15}$ Bacterial cells in the biofilm are physiologically different from their planktonic counterparts and express specific protective factors, such as antibiotic efflux pumps and enzymes capable of neutralizing antibiotic drugs. ${ }^{17}$ These bacterial cells may escape from the effect of antimicrobial agents. These cells are known as persisters, and even though they may not be resistant to the employed antibiotic, they do not grow.

Owing to the complex and heterogeneous nature of biofilm, several mechanisms of resistance are triggered at the same time within a single community of micro-organisms. ${ }^{12}$ The exposure of slowly reproducing bacteria to antibacterial drugs may trigger the generation of mechanisms of antibiotic resistance in the micro-organisms. This antibiotic resistance makes the treatment of infection and the eradication of colonized prosthetic or native tissue surfaces, a challenge for physicians, ${ }^{17}$ risking the patient's life or, at best, causing the loss of the affected port.

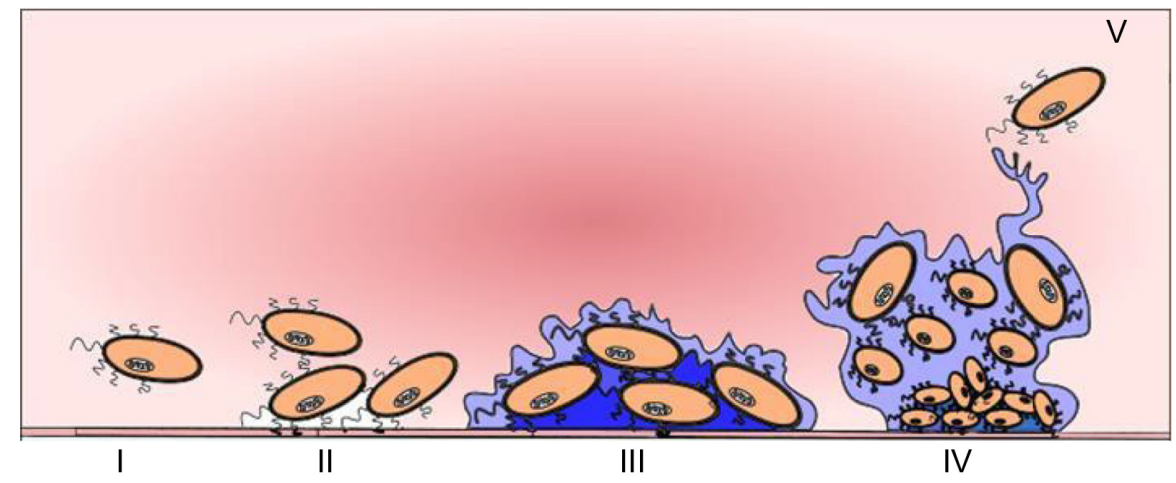

Figure I Biofilm development.

Notes: I Planktonic bacteria; II Attachment of bacterial cells; III Bacterial cells form a biofilm using their pili and exopolysaccharide; IV Mature biofilm; V Release of microorganisms to the bloodstream. 


\section{From biofilm generation to port complications}

Port-related complications can be classified as mechanical or infectious. Although both types of complications may appear at any time after implantation, usually mechanical complications appear soon after implantation (around 0.40/1,000 IVD days $\left.^{6}\right)$, while infection-related complications are most likely to appear later on. ${ }^{18}$

The micro-organisms most commonly implicated in CRBSI associated with percutaneously inserted, noncuffed catheters are coagulase-negative Staphylococcus (CoNS), Staphylococcus aureus, enteric gram-negative bacilli, Pseudomonas species, and Candida species. ${ }^{2,19}$ Grampositive cocci are responsible for around $65 \%$ of cases of catheter-related bacteremia (CRB), ${ }^{20,21}$ and are the most frequent gram-positive cocci involved in colonization and biofilm formation of intravenous devices. ${ }^{10}$ Staphylococcus aureus deserve a special mention because of the virulence of the pathogen and its ability to cause more serious complications that may risk patients' lives. ${ }^{2}$

\section{Clinical manifestations of CRBSI}

CRI represent a wide spectrum of frequent and sometimes severe complications associated with the use of venous devices. The clinical scenarios include skin and soft tissue infections, subcutaneous pocket infection, tunnelitis, CRB, septic thrombophlebitis, infective endocarditis, metastatic septic dissemination such as septic pulmonary embolisms, osteomyelitis, spleen and liver abscesses, and in the worst cases, septic shock.

\section{Diagnosis of CRBSI}

CRBSI is diagnosed when no other detectable focus of infection, except the catheter, is identified. Clinical diagnosis is usually based on fever $\left(>38^{\circ} \mathrm{C}\right)$, chills or hypotension, a tunneled venous catheter in use 48 hours prior to the development of infection, and a positive blood culture with isolation of the same micro-organism from the catheter and bloodstream. There is local purulence (with the same microorganism that is in blood cultures), increased warmth and induration extending at least $2 \mathrm{~cm}$ from the $\mathrm{CVC}$ insertion site, disappearance of signs of infection and a return to a normal temperature within 24 hours after catheter removal without antibiotic treatment, and a positive quantitative catheter culture, with isolation of the same micro-organism from the catheter and bloodstream. ${ }^{22}$ Diagnosis of CRBSI requires that the same micro-organism grow from at least one blood culture and from the culture of the catheter tip. In the case of less virulent micro-organisms, such as Micrococcus, Corynebacterium, and Bacillus species, at least two positive results of blood cultures on samples obtained from different sites are required. ${ }^{2}$

Risk factors for CRI are associated with the time of catheterization and handling of the venous catheter, ${ }^{3,11,21}$ the variables related to the type of tunneled catheter, ${ }^{4,21}$ catheter insertion technique, ${ }^{3,4}$ catheter placement, ${ }^{4}$ hematological malignancies, ${ }^{3,20,21}$ patient age, ${ }^{20}$ parenteral nutrition administration, ${ }^{19,23}$ immunosuppression, ${ }^{24}$ and prolonged neutropenia. ${ }^{6}$

Withdrawing the catheter removes the source of infection and enables microbiological analysis of the catheter, but the decision to remove a catheter should take into consideration at least three factors: the type of the catheter; the microorganism involved in the infection; and clinical status of the patient. ${ }^{25}$

\section{Conservative diagnosis of CRB}

There are two methods for in situ diagnosis of CRB: quantitative culture of paired blood samples, and differential time to positivity of catheter blood sample compared to peripheral vein blood culture. Quantitative culture of paired blood samples looks for the correlation between a positive differential quantitative blood culture threefold greater than identical bacterial colony count in peripheral vein blood specimen. ${ }^{2}$ This test is considered indicative of CRB with $77.8 \%$ sensitivity, $100 \%$ specificity, and an overall accuracy of $91.7 \%$. When it is not possible to obtain blood from peripheral vein puncture, or if the patient has a multiple lumen catheter, Infectious Diseases Society of America (IDSA) guidelines suggest that diagnosis of $\mathrm{CRB}$ can be assessed by isolation of $\geq 100$ colony-forming units (CFU)/mL bacteria from a single quantitative blood culture drawn from one of the lumens of the catheter. ${ }^{2}$ For multiple lumen venous catheters, blood cultures should be drawn from all lumens in order to increase the sensitivity of a single blood culture sample. ${ }^{26}$ Not sampling one of the lumens may result in a failure to diagnose CRB. ${ }^{27}$

In differential time to positivity of catheter blood sample compared to peripheral vein blood culture, ${ }^{2,28}$ a cut-off differential time to positivity value of 120 minutes has $91 \%$ specificity and $94 \%$ sensitivity for the diagnosis of CRB. ${ }^{28}$

\section{Diagnosis of CRB after catheter removal}

The challenge is to solve the infection without losing the catheter. However, even after catheter removal, the 
microbiological testing does not always demonstrate the micro-organism involved in the infectious process. Traditionally, the diagnosis of CRB requires removal of the catheter in order to culture the $4 \mathrm{cms}$ of the catheter tip. ${ }^{29}$ For ports, culture of the material inside the reservoir is more sensitive than catheter tip culture. ${ }^{30}$ When ports are removed, the silicone membrane is cut in order to open the reservoir, to vortex and culture the septum of the device using a quantitative method. ${ }^{31} \mathrm{~A}$ cut-off of $\geq 10^{3} \mathrm{CFU}$ is used to differentiate significant from insignificant colonization. ${ }^{29}$ However, some micro-organisms, such as $S$. aureus, Candida species, or gram-negative bacilli, may have a lower CFU cut-off.

The quantitative method is based on flushing the catheter lumen with $2 \mathrm{~mL}$ of brain-heart infusion broth, which is diluted tenfold; $0.1 \mathrm{~mL}$ of each dilution is then streaked onto blood agar. The catheter lumen is considered significantly colonized if bacterial count is $\geq 10^{3}$ CFU. ${ }^{11,32}$ The quantitative catheter segment cultures have the highest sensitivity (80\%-100\%) and specificity (more than 90\%), when compared with semiquantitative or qualitative broth cultures, to diagnose $\mathrm{CRB} .^{33}$

The culture of the sonicated catheter has been shown to be useful in diagnosing CRB. This technique can recover micro-organisms from the external and the internal surface of the catheter. Sonication methods allow quantification of CFU removed from a catheter. A catheter culture in which $\geq 10^{2}$ $\mathrm{CFU}$ grow and has associated blood cultures in the previous 48 hours is used to diagnose CRB. ${ }^{34}$

Semiquantitative roll-plate culture technique has been developed to assess the intraluminal and extraluminal colonization of the catheter. The semiquantitative method is performed rolling the catheter across the blood agar plate four times. The catheter tip is considered colonized, or it is suggestive of CRBSI, if the bacterial count is $\geq 15$ CFU. $^{9}$

Qualitative broth culture of port segments has high sensitivity for microbiological diagnosis, but it cannot distinguish infection from contamination of the catheter. Often, a catheter is removed after antimicrobial treatment has begun. This situation could reduce the sensitivity of the cultures, leaving the diagnosis of CRI as presumptive.

\section{Catheter-related bloodstream infection treatment}

$\mathrm{CRB}$ is a major cause of patient morbidity, premature catheter removal, and increased treatment cost. When CRB is diagnosed, the most effective therapeutic strategy is to remove the device. Catheter retention is associated with a high risk of bacteremia recurrence. ${ }^{35}$ The catheter has to be removed if there are signs of subcutaneous tunnel infection, suppurative phlebitis, septic shock, peripheral or pulmonary embolization, clinical suggestion of infective endocarditis, persistent bacteremia, recurrent infection despite adequate medical treatment, or when the micro-organism involved is identified as S. aureus, Candida spp., or Mycobacterium spp. ${ }^{2}$ However, in many cases catheter removal is avoided as first step of treatment if the venous catheter was surgically implanted or may not be easily replaced, or if the patient is hemodynamically stable. ${ }^{36}$ In those cases, and according to the clinical guides, the use of the venous device is stopped, and local and systemic antibiotic treatment is initiated. ${ }^{2}$

\section{Systemic antibiotic treatment}

With uncomplicated CRBSI, if the catheter is removed, systemic antibiotic therapy is administered for up to 7 days. But if a tunnel infection or port abscess is diagnosed, it is necessary to remove the catheter, drain the tissue affected, and administer antibiotic treatment for 7 to 10 days, in the absence of concomitant bacteremia or fungemia. ${ }^{2}$ With purulent local complications, systemic antibiotic treatment without catheter removal has been demonstrated to be ineffective. In a series of 102 patients with hemodialysis catheters, Marr et al described treatment failure in $68 \%$ of cases of attempted catheter salvage. Most of these cases were related to gram-positive cocci infections, and the worst prognosis was associated with $S$. aureus serious complications. ${ }^{37}$ The choice of antimicrobial agent depends on microbiological isolates, but this is not always possible. For this reason, it is often necessary to start with empiric antibiotic treatment. ${ }^{38}$ In this clinical scenario, the selection of the antimicrobial agent would consider not only the micro-organism involved, but the pharmacodynamics properties of the antimicrobial agent. It is a cautious measure to select a bactericidal over a bacteriostatic antimicrobial agent. To achieve therapeutic effectiveness, glycopeptides require maintaining AUC/MIC (area under the curve/minimum inhibitory concentration) during the dose interval. Beta-lactams require maintaining their concentration over the MIC during the dose interval.

Whenever the decision of maintaining the catheter in place has been made, empiric antibiotic therapy has to be administered intravenously and locally (antibiotic lock technique [ALT]) for 10 to 14 days. In cases of multiple-lumen catheters, the administration of antibiotics should rotate among different lumens. ${ }^{38}$ According to the IDSA guidelines, when the involved micro-organism is a CoNS or a gramnegative bacilli, and there are positive blood cultures drawn from the catheter, but negative from peripheral vein, ALT 
has to be considered from 10 to 14 days, without systemic antibiotic treatment. $^{2}$

\section{Antibiotic lock technique and clinical experience}

Local antibiotic treatment, or ALT, was described for the first time in 1988 by Messing et a ${ }^{39}$ for treatment of CRB associated with parenteral nutrition. ALT consists of the infusion of a concentrated antibiotic solution in a small volume to fill the lumen catheter. The rationality of this technique is to expose the interior walls of the catheter to high concentrations of an antibiotic that may penetrate the biofilm, and therefore to achieve bacterial eradication. However, despite the efforts to conserve a highly needed venous catheter, the goal is not always reached, making the biofilm the principal source for chronic infections and the cause of catheter removal. It is important to note that even with microbiological diagnosis, the bacterial resistance profiles obtained in clinical laboratories may not predict differences in the eradication effect of the antimicrobial agents in biofilms. ${ }^{40}$ At present, the selection of the most effective antimicrobial agent, the optimal antimicrobial concentration, and the best interval of time required for antibiotic lock solutions have yet to be defined. Antimicrobials agents that display postantibiotic effect, such as fluoroquinolones and aminoglycosides, may not require higher concentrations for antibiotic lock solutions, as glycopeptides or beta-lactams do.

Although ALT was described in 1988, the first randomized clinical trial had to wait until 2005, when Rijnders et al carried out a study to compare antibiotic lock treatment versus placebo in CRBSI. ${ }^{41}$ Despite having to stop the trial because of patient recruitment difficulties, their study showed that in patients with long-term intravenous device-related bloodstream infection, the use of an antibiotic lock solution in addition to parenterally administered antibiotics reduced the failure rate to cure the CRBSI from $57 \%$ to $33 \%$. In this line, Fernandez-Hidalgo et al concluded in an open, noncomparative study of 115 episodes of CRB in 98 patients that the combination of ALT with vancomycin 2,000 mg/L or ciprofloxacin 2,000 mg/L for gram-positive or -negative micro-organisms, respectively, with systemic antibiotics is effective to treat CRB, especially in gram-negative and CoNS CRB episodes. ${ }^{42}$ Their patients received a median of 12 days of ALT and systemic treatment, and had an overall treatment success of $82 \%$. They attributed their high cure rate to the fact that the catheter was not used during treatment but rather exposed to high antibiotic concentrations, and the concurrence of systemic antibiotic therapy.
Even though there are no randomized clinical trials that support them, glycopeptides are considered the drugs of choice for empiric treatment, as the incidence of methicillin resistance is high among CoNS, and there is a possibility of having an infection due to methicillin-resistant $S$. aureus, especially in medical health care environments. According to the experience of the authors of this review, ALT is a safe and effective treatment for port-related BSI when combined with systemic antibiotic therapy. ${ }^{43,44}$ Among the studied antibiotics, teicoplanin has shown better port survival rate compared to vancomycin when both were used for ALT ${ }^{45}$ Del Pozo et al also evaluated the effectiveness of ALT in port-related BSI with micro-organisms different than CoNS. They reported that systemic treatment combined with ALT is effective and safe for treatment of port-related BSI, if patients are stable and have no septic syndrome. ${ }^{43}$

The efficacy of the antibiotic solution during this time is also a concern. Soriano et al carried out a clinical assay in patients with hemodialysis catheters. They determined the vancomycin concentration every 48 hours and reported that there exists a decreasing gradient of vancomycin concentration of almost $50 \%$, from proximal to distal segments of subclavian and femoral hemodialysis catheters. ${ }^{46}$ Although the methodology of their assay may not necessarily reproduce the in vivo clinical situation of the antibiotic solution, their findings support the IDSA recommendation for replacing the antibiotic solution every 24 hours. $^{2}$ It is necessary to elucidate the best time for antibiotic replacement with certainty of adequate concentration and antimicrobial activity with the passage of time.

One of the issues with ALT use is related to the high concentration of antibiotic used for the lock solution, and the possible side effects that may result from the solution passing into the bloodstream. Although there are few reports regarding this aspect, Elian et al reported that there was no significant change in the serum kinetics of vancomycin in two patients treated with systemic and ALT vancomycin. ${ }^{47} \mathrm{In}$ a recent review focused on pharmacological stability of lock solutions, Morales-Molina et al found that the most studied solutions were those with vancomycin and ciprofloxacin. According to them, the best alternatives for antibiotic lock solution against gram-positive cocci, methicillin-resistant Staphylococcus aureus (MRSA) included, were vancomycin alone $(2-10 \mathrm{mg} / \mathrm{mL})$ or vancomycin $(0.5-10 \mathrm{mg} / \mathrm{mL})$ combined with heparin $(100-5,000 \mathrm{U} / \mathrm{mL}) .{ }^{48}$ Similar results in patients with hemodialysis catheters were experienced by Poole et al, using ALT combined with systemic antibiotic treatment. They observed an overall successful treatment of 
$70 \%$ of patients with CRB using ALT with vancomycin and ceftazidime, unless microbiological sensitivity had required modification of the antibiotic administered, for both local and systemic antibiotic treatment. ${ }^{49}$

Regarding treatment, using ALT with vancomycin, there is contradictory published information. Megged et $\mathrm{al}^{50}$ described a series of 23 patients with an overall success rate of $30 \%$. They observed that hemodialysis catheters had significantly higher salvage rates than ports $(75 \%$ versus $18 \%$ ). In their study, all patients with an early or late relapse had a port. They attributed the difference in cure rate between catheters to variations in biofilm formation resulting from more complex structures within the ports, and the fact that they began ALT after 48 hours of bacteremia after appropriate systemic antimicrobial therapy had failed to treat the infection. ${ }^{50}$ Failure in treatment might be related to the virulence of the micro-organism involved in the infection. Several reports include $S$. aureus biofilm-related venous device infection with unsuccessful attempts of cure, and early decision of catheter removal due to the risk of serious complications, before trying to use the ALT. ${ }^{41,42}$ Maya et al conducted a prospective study, following 113 hemodialysis patients with $S$. aureus bacteremia trying to assess the outcome of patients treated with ALT. They reported clinical cure in almost $40 \%$ of patients treated with ALT and described $25 \%$ of serious complications in patients who experienced persistent fever. ${ }^{51}$

The search for different antibiotic options for CRBSI treatment continues. Del Pozo et al described 13 patients with long-term catheters (six ports and seven Hickman) treated with daptomycin lock therapy. All patients had gram-positive CRBSI. The authors described clinical cure and blood culture sterilization in $85 \%$ of the patients. ${ }^{44}$

The appropriate duration for ALT is another unresolved question. Evidence exists that treatment duration shorter than 10-14 days might be enough for resolving biofilm-related venous catheter infections. A brief report of 3 days of ALT that resolved $81 \%$ of CRI was published in $2011 .{ }^{52} \mathrm{~A}$ previous report of 14 patients showed that a 3-day course of ALT associated with 7 days of levofloxacin $500 \mathrm{mg}$ achieved catheter salvage in 12 cases. ${ }^{53}$ In spite of reported data, the question is still open. It is necessary to obtain evidence through clinical trials that may ensure that prolonging the antibiotic lock time inside the port is at least as effective and safe, for the patient, as current clinical guidelines.

\section{Treatment failure criteria}

Treatment failure is considered when the port has to be removed during local and systemic antimicrobial therapy, or after finishing antibiotic treatment due to persistence of fever ( $>72$ hours after initiation of appropriate antibiotic therapy), or bacteremia ( $>72$ hours) or venous access port culture with the same micro-organism after the end of the treatment. ${ }^{2}$

\section{Prevention strategies for CRI}

There are several published recommendations, based on clinical trials, to prevent CRI (Table 1). Some of them include simple and practical interventions that decrease the burden of venous catheter-related infections. ${ }^{54-56}$ It is mandatory to perform hand hygiene before catheter insertion or manipulation. It is also imperative to disinfect catheter hubs, needleless connectors, and injection ports before accessing the catheter. For this purpose, preparations of alcoholic chlorhexidine and 70\% alcohol are recommended. ${ }^{55,56}$ All successful preventive strategies incorporate three distinct methods to decrease CRI: diminish colonization of the catheter insertion site and hubs; minimizing the spread of micro-organisms from the skin to the catheter wall; and reducing microbial spread through the lumen catheter toward the bloodstream. ${ }^{54}$

The use of antibiotic prophylaxis at moment of catheter implantation to prevent $\mathrm{CRB}$ has always been questioned. In a survey performed in 2007, 606 members of the IDSA and the Pediatric Infectious Disease Society were asked about the use of ALT and prophylaxis in their clinical practice. Only $19 \%$ of the infectious diseases physicians reported using ALT prophylaxis. One hundred and fifty members reported using ALT to treat patients with CoNS CRBSI. Of them, 89\% preferred vancomycin alone. Fifty-five members recommended a length of treatment of 10-14 days. ${ }^{57}$ Data from 1985 showed that prophylaxis with vancomycin at the time of catheter insertion did not reduce incidence of CRB. ${ }^{58}$ Other studies using vancomycin and teicoplanin were not able to rule out the possibility of a beneficial effect. ${ }^{54}$ Recently, a study comparing vancomycin and linezolid for prophylaxis of CRBSI in patients with temporary nontunneled hemodialysis catheters showed no significant CRBSI incidence rate between both antibiotics; however, none of the patients locked with linezolid experienced CRBSI during the follow-up period. ${ }^{59}$ There is also concern about inducing antibiotic resistance if bacterial cells are exposed to inadequate concentrations of antimicrobial agents. It is reasonable to try to avoid the use of antimicrobial therapeutic agents as pharmacological prevention of CRB. Moreover, IDSA recommends against the routine use of prophylactic antibiotic lock solutions. ${ }^{2,56}$ The use of ALT as prophylaxis for CRB has to be circumscribed to patients with limited venous access and a history of recurrent 
Table I Summary of some RCT and controlled studies' published articles on catheter infection and prevention of CRBSI

\begin{tabular}{|c|c|c|c|c|}
\hline Design & $\mathbf{N}$ & Intervention & Main conclusion & Reference \\
\hline Retrospective & 54 & Oral prophylaxis with doxycycline in HCT patients & No CVC infection in the doxycycline group & 62 \\
\hline Retrospective & 459 & Single dose of antibiotic during placement of TIVPAs & Decrease of CRI & 63 \\
\hline Observational & 179 & Perioperative prophylactic cefuroxime administration & No CRBSI reported & 64 \\
\hline $\begin{array}{l}\text { Crossover, } \\
\text { randomized }\end{array}$ & 26 & Oral prophylaxis with novobiocin and rifampin & Effectiveness of antibiotic prophylaxis & 65 \\
\hline Randomized & 40 & 3 days of vancomycin during insertion of CVC & $\begin{array}{l}\text { Bacteremic episodes reduced } \\
\text { in the vancomycin group }\end{array}$ & 66 \\
\hline $\begin{array}{l}\text { Randomized, } \\
\text { controlled }\end{array}$ & 148 & Amoxicillin prophylaxis to prevent CRI & $\begin{array}{l}\text { Failure to demonstrate benefit } \\
\text { of amoxicillin prophylaxis }\end{array}$ & 67 \\
\hline Randomized & 88 & Teicoplanin before insertion of Hickman catheter & Lower incidence of CRS in teicoplanin arm & 68 \\
\hline $\begin{array}{l}\text { Randomized, } \\
\text { controlled }\end{array}$ & 98 & Vancomycin during placement of long-term CVC & Failure to reduce CRS & 69 \\
\hline Randomized & 47 & Single dose of vancomycin at time of insertion of CVC & Failure to reduce CRS & 70 \\
\hline \multicolumn{5}{|c|}{ Ethanol lock technique } \\
\hline Retrospective & 31 & $70 \%$ ethanol lock solution followed by $\mathrm{NaCl} 0.9 \%$ flushing & Reduced CRBSI-related admissions & 71 \\
\hline $\begin{array}{l}\text { Randomized, } \\
\text { double-blind }\end{array}$ & 376 & $\begin{array}{l}70 \% \text { ethanol vs placebo for } 15 \text { minutes followed } \\
\text { by } \mathrm{NaCl} 0.9 \% \text { flushing }\end{array}$ & No significant difference between groups & 72 \\
\hline $\begin{array}{l}\text { Prospective, } \\
\text { open-label }\end{array}$ & 12 & Overnight $70 \%$ ethanol lock solution & No significant difference observed & 73 \\
\hline \multicolumn{5}{|c|}{ Antiseptic-impregnated and antibiotic-impregnated catheters } \\
\hline Randomized & 133 & $\begin{array}{l}\text { Chlorhexidine and silver sulfadiazine catheters vs } \\
\text { nonimpregnated }\end{array}$ & $\begin{array}{l}\text { Failure to reduce incidence } \\
\text { of colonization or CRBSI }\end{array}$ & 74 \\
\hline Randomized & 204 & $\begin{array}{l}\text { Chlorhexidine and silver sulfadiazine catheter vs } \\
\text { no antiseptic catheter }\end{array}$ & No significant difference between groups & 75 \\
\hline $\begin{array}{l}\text { Randomized, } \\
\text { double-blind }\end{array}$ & 370 & $\begin{array}{l}\text { Minocycline and rifampin catheters vs no antimicrobial } \\
\text { catheters }\end{array}$ & Antimicrobial catheters decreased CRI & 76 \\
\hline Randomized & 228 & $\begin{array}{l}\text { Chlorhexidine and silver sulfadiazine catheters vs } \\
\text { no antiseptic catheters }\end{array}$ & $\begin{array}{l}\text { Antiseptic-bonded catheters have } \\
\text { lower colonization rate }\end{array}$ & 77 \\
\hline Randomized & 817 & $\begin{array}{l}\text { Chlorhexidine and sulfadiazine vs minocycline } \\
\text { and rifampin catheters }\end{array}$ & $\begin{array}{l}\text { Antibiotic catheters had lower } \\
\text { colonization and CRBSI }\end{array}$ & 78 \\
\hline $\begin{array}{l}\text { Randomized, } \\
\text { controlled }\end{array}$ & 119 & $\begin{array}{l}\text { Chlorhexidine and sulfadiazine catheters vs } \\
\text { nonimpregnated }\end{array}$ & $\begin{array}{l}\text { Reduction of colonization } \\
\text { in the antibiotic arm }\end{array}$ & 79 \\
\hline $\begin{array}{l}\text { Randomized, } \\
\text { double-blind }\end{array}$ & 538 & $\begin{array}{l}\text { Chlorhexidine and silver sulfadiazine catheters vs } \\
\text { nonimpregnated }\end{array}$ & No significant difference between groups & 80 \\
\hline $\begin{array}{l}\text { Randomized, } \\
\text { controlled }\end{array}$ & 158 & $\begin{array}{l}\text { Chlorhexidine and silver sulfadiazine catheters vs } \\
\text { nonimpregnated }\end{array}$ & Reduced incidence of CRI & 81 \\
\hline $\begin{array}{l}\text { Randomized, } \\
\text { double-blind }\end{array}$ & 281 & Coated minocycline and rifampin CVC & $\begin{array}{l}\text { Antibiotic-coated } \mathrm{CVC} \text { reduced } \\
\text { colonization and } \mathrm{BSI}\end{array}$ & 82 \\
\hline Randomized & 233 & $\begin{array}{l}\text { Chlorhexidine and sulfadiazine catheters vs } \\
\text { nonimpregnated }\end{array}$ & $\begin{array}{l}\text { Reduction of colonization } \\
\text { in the antibiotic group }\end{array}$ & 83 \\
\hline Randomized & 20 & Teicoplanin-coated CVC vs noncoated antibiotic CVC & No significant difference between groups & 84 \\
\hline
\end{tabular}

Abbreviations: BSI, bloodstream infection; CRBSI, catheter-related bloodstream infection; CRI, catheter-related infection; CRS, catheter-related sepsis; CVC, central venous catheter; HCT, hematopoietic cell transplantation; RCT, randomized controlled trial; TIVPA, totally implanted venous port access; vs, versus.

central line-associated BSI, and to patients who are at higher risk for severe sequels from central line-associated BSI. ${ }^{55}$ Recently, an open-labeled, randomized clinical trial showed noninferiority of normal saline compared with heparin to lock ports. CRBSI was 0.03 per 1,000 catheter days in the normal saline group and 0.10 per 1,000 catheter days in the heparin group. ${ }^{60}$ This data may support the use of no antimicrobial agents to prevent CRBSI.

\section{Future directions}

Diagnosing and treating CRBSI is a medical challenge. It is important to remember that simple and proven common- sense measures such as hand washing, using full barrier precautions during CVC insertion, cleaning the skin with chlorhexidine, avoiding femoral catheter insertion, and removing unnecessary catheters have demonstrated a reduce in rates of CRBSI. ${ }^{61}$ New molecular technologies are available to obtain faster diagnosis of CRBSI, such as multiplex polymerase chain reaction (PCR) in blood cultures obtained from the ports. Promising innovations for patient care include the development of devices that prevent bacterial growth and biofilm development, new medical catheters with fibrin inhibitors, the use of functional antibodies against specific targets of micro-organisms, and the use of enzymes to break 
down the biofilm integrity or to modify protein expression of bacterial cells within the biofilm. At present, there are still gaps to be filled, such as the best antimicrobial agent to treat CRBSI, and the period of time that an antibiotic solution may remain inside the lumen of the port without losing antimicrobial activity. It is necessary to improve our knowledge and practice of actual medical care through randomized clinical trials in order to overcome biofilm-related infections.

\section{Disclosure}

The authors report no conflicts of interest in this work.

\section{References}

1. Niederhuber JE, Ensminger W, Gyves JW, Liepman M, Doan K, Cozzi E. Totally implanted venous and arterial access system to replace external catheters in cancer treatment. Surgery. 1982;92(4):706-712.

2. Mermel LA, Allon M, Bouza E, et al. Clinical practice guidelines for the diagnosis and management of intravascular catheter-related infection: 2009 Update by the Infectious Diseases Society of America. Clin Infect Dis. 2009;49(1):1-45.

3. Kock HJ, Pietsch M, Krause U, Wilke H, Eigler FW. Implantable vascular access systems: experience in 1500 patients with totally implanted central venous port systems. World J Surg. 1998;22(1): 12-16.

4. Maki DG, Kluger DM, Crnich CJ. The risk of bloodstream infection in adults with different intravascular devices: a systematic review of 200 published prospective studies. Mayo Clin Proc. 2006;81(9): 1159-1171.

5. Chitnis AS, Edwards JR, Ricks PM, Sievert DM, Fridkin SK, Gould CV. Device-associated infection rates, device utilization, and antimicrobial resistance in long-term acute care hospitals reporting to the National Healthcare Safety Network, 2010. Infect Control Hosp Epidemiol. 2012;33(10):993-1000.

6. Bassi KK, Giri AK, Pattanayak M, Abraham SW, Pandey KK. Totally implantable venous access ports: retrospective review of longterm complications in 81 patients. Indian J Cancer. 2012;49(1): 114-118.

7. Armstrong D, Cohen J, editors. Infectious Diseases. Vol 2. London: Mosby; 1999.

8. Costerton JW, Stewart PS, Greenberg EP. Bacterial biofilms: a common cause of persistent infections. Science. 1999;284(5418):1318-1322.

9. Maki DG, Weise CE, Sarafin HW. A semiquantitative culture method for identifying intravenous-catheter-related infection. $N$ Engl J Med. 1977;296(23):1305-1309.

10. Raad I, Costerton W, Sabharwal U, Sacilowski M, Anaissie E, Bodey GP. Ultrastructural analysis of indwelling vascular catheters: a quantitative relationship between luminal colonization and duration of placement. J Infect Dis. 1993;168(2):400-407.

11. Liñares J, Sitges-Serra A, Garau J, Pérez JL, Martín R. Pathogenesis of catheter sepsis: a prospective study with quantitative and semiquantitative cultures of catheter hub and segments. J Clin Microbiol. 1985;21(3): 357-360.

12. Mah TF, O'Toole GA. Mechanisms of biofilm resistance to antimicrobial agents. Trends Microbiol. 2001;9(1):34-39.

13. Costerton JW, Lewandowski Z, DeBeer D, Caldwell D, Korber D, James G. Biofilms, the customized microniche. J Bacteriol. 1994; 176(8):2137-2142.

14. Sauer K, Camper AK, Ehrlich GD, Costerton JW, Davies DG. Pseudomonas aeruginosa displays multiple phenotypes during development as a biofilm. J Bacteriol. 2002;184(4):1140-1154.

15. Prosser BL, Taylor D, Dix BA, Cleeland R. Method of evaluating effects of antibiotics on bacterial biofilm. Antimicrob Agents Chemother. 1987;31(10):1502-1506.
16. Carratalà J. The antibiotic-lock technique for therapy of 'highly needed' infected catheters. Clin Microbiol Infect. 2002;8(5):282-289.

17. del Pozo JL, Patel R. The challenge of treating biofilm-associated bacterial infections. Clin Pharmacol Ther. 2007;82(2):204-209.

18. Di Carlo I, Biffi R, editors. Totally Implantable Venous Access Devices. Management in Mid-and Long-Term Clinical Setting. Milan: SpringerVerlag Italia, 2012.

19. Wintenberger C, Epaulard O, Hincky-Vitrat V, et al. Outcome of central venous catheter-related bacteraemia according to compliance with guidelines: experience with 91 episodes. J Hosp Infect. 2012;80(3): 245-251.

20. Groeger JS, Lucas AB, Thaler HT, et al. Infectious morbidity associated with long-term use of venous access devices in patients with cancer. Ann Intern Med. 1993;119(12):1168-1174.

21. Adler A, Yaniv I, Steinberg R, et al. Infectious complications of implantable ports and Hickman catheters in paediatric haematology-oncology patients. J Hosp Infect. 2006;62(3):358-365.

22. Blot F, Nitenberg G, Brun-Buisson C. New tools in diagnosing catheterrelated infections. Support Care Cancer. 2000;8(4):287-292.

23. Chen IC, Hsu C, Chen YC, et al. Predictors of bloodstream infection associated with permanently implantable venous port in solid cancer patients. Ann Oncol. 2013;24(2):463-468.

24. Domingo P, Fontanet A, Sánchez F, Allende L, Vazquez G. Morbidity associated with long-term use of totally implantable ports in patients with AIDS. Clin Infect Dis. 1999;29(2):346-351.

25. Raad II, Bodey GP. Infectious complications of indwelling vascular catheters. Clin Infect Dis. 1992;15(2):197-208.

26. Robinson JL. Sensitivity of a blood culture drawn through a single lumen of a multilumen, long-term, indwelling, central venous catheter in pediatric oncology patients. J Pediatr Hematol Oncol. 2002;24(1): $72-74$.

27. Guembe M, Rodríguez-Créixems M, Sánchez-Carrillo C, Pérez-Parra A, Martín-Rabadán P, Bouza E. How many lumens should be cultured in the conservative diagnosis of catheter-related bloodstream infections? Clin Infect Dis. 2010;50(12):1575-1579.

28. Blot F, Nitenberg G, Chachaty E, et al. Diagnosis of catheter-related bacteraemia: a prospective comparison of the time to positivity of hub-blood versus peripheral-blood cultures. Lancet. 1999;354(9184): 1071-1077.

29. Brun-Buisson C, Abrouk F, Legrand P, Huet Y, Larabi S, Rapin M. Diagnosis of central venous catheter-related sepsis. Critical level of quantitative tip cultures. Arch Intern Med. 1987;147(5):873-877.

30. Douard MC, Arlet G, Longuet P, et al. Diagnosis of venous access port-related infections. Clin Infect Dis. 1999;29(5):1197-1202.

31. Longuet P, Douard MC, Arlet G, Molina JM, Benoit C, Leport C. Venous access port-related bacteremia in patients with acquired immunodeficiency syndrome or cancer: the reservoir as a diagnostic and therapeutic tool. Clin Infect Dis. 2001;32(12):1776-1783.

32. Cleri DJ, Corrado ML, Seligman SJ. Quantitative culture of intravenous catheters and other intravascular inserts. J Infect Dis. 1980;141(6): 781-786.

33. Siegman-Igra Y, Anglim AM, Shapiro DE, Adal KA, Strain BA, Farr BM. Diagnosis of vascular catheter-related bloodstream infection: a meta-analysis. J Clin Microbiol. 1997;35(4):928-936.

34. Sherertz RJ, Raad II, Belani A, et al. Three-year experience with sonicated vascular catheter cultures in a clinical microbiology laboratory. J Clin Microbiol. 1990;28(1):76-82.

35. Raad I, Davis S, Khan A, Tarrand J, Elting L, Bodey GP. Impact of central venous catheter removal on the recurrence of catheter-related coagulase-negative staphylococcal bacteremia. Infect Control Hosp Epidemiol. 1992;13(4):215-221.

36. Berrington A, Gould FK. Use of antibiotic locks to treat colonized central venous catheters. J Antimicrob Chemother. 2001;48(5): 597-603.

37. Marr KA, Sexton DJ, Conlon PJ, Corey GR, Schwab SJ, Kirkland KB. Catheter-related bacteremia and outcome of attempted catheter salvage in patients undergoing hemodialysis. Ann Intern Med. 1997;127(4): 275-280. 
38. Rodríguez-Baño J. Selection of empiric therapy in patients with catheterrelated infections. Clin Microbiol Infect. 2002;8(5):275-281.

39. Messing B, Peitra-Cohen S, Debure A, Beliah M, Bernier JJ. Antibioticlock technique: a new approach to optimal therapy for catheter-related sepsis in home-parenteral nutrition patients. JPEN J Parenter Enteral Nutr. 1988;12(2):185-189.

40. Monzón M, Oteiza C, Leiva J, Lamata M, Amorena B. Biofilm testing of Staphylococcus epidermidis clinical isolates: low performance of vancomycin in relation to other antibiotics. Diagn Microbiol Infect Dis. 2002;44(4):319-324.

41. Rijnders BJ, Van WijngaerdenE, Vandecasteele SJ, Stas M, Peetermans WE. Treatment of long-term intravascular catheter-related bacteraemia with antibiotic lock: randomized, placebo-controlled trial. J Antimicrob Chemother. 2005;55(1):90-94.

42. Fernandez-Hidalgo N, Almirante B, Calleja R, et al. Antibiotic-lock therapy for long-term intravascular catheter-related bacteraemia: results of an open, non-comparative study. J Antimicrob Chemother. 2006;57(6):1172-1180.

43. Del Pozo JL, Alonso M, Serrera A, Hernaez S, Aguinaga A, Leiva J. Effectiveness of the antibiotic lock therapy for the treatment of port-related enterococci, Gram-negative, or Gram-positive bacilli bloodstream infections. Diagn Microbiol Infect Dis. 2009;63(2): 208-212.

44. Del Pozo JL, Rodil R, Aguinaga A, et al. Daptomycin lock therapy for grampositive long-term catheter-related bloodstream infections. Int $J$ Clin Pract. 2012;66(3):305-308.

45. Del Pozo JL, García Cenoz M, Hernáez S, et al. Effectiveness of teicoplanin versus vancomycin lock therapy in the treatment of port-related coagulase-negative staphylococci bacteraemia: a prospective case-series analysis. Int J Antimicrob Agents. 2009;34(5):482-485.

46. Soriano A, Bregada E, Marqués JM, et al. Decreasing gradient of antibiotic concentration in the lumen of catheters locked with vancomycin. Eur J Clin Microbiol Infect Dis. 2007;26(9):659-661.

47. Elian JC, Frappaz D, Ros A, et al. [Study of serum kinetics of vancomycin during the "antibiotic-lock" technique]. Arch Fr Pediatr. 1992;49(4): 357-360. French.

48. Morales-Molina JA, Mateu-de Antonio J, Grau S, Segura M, Acosta P. [Stability: a factor to consider in antibiotic-lock solutions]. Enferm Infecc Microbiol Clin. 2010;28(2):104-109. Spanish.

49. Poole CV, Carlton D, Bimbo L, Allon M. Treatment of catheterrelated bacteraemia with an antibiotic lock protocol: effect of bacterial pathogen. Nephrol Dial Transplant. 2004;19(5):1237-1244.

50. Megged O, Shalit I, Yaniv I, Fisher S, Livni G, Levy I. Outcome of antibiotic lock technique for persistent central venous catheter-associated coagulase-negative Staphylococcus bacteremia in children. Eur J Clin Microbiol Infect Dis. 2010;29(2):157-161.

51. Maya ID, Carlton D, Estrada E, Allon M. Treatment of dialysis catheter-related Staphylococcus aureus bacteremia with an antibiotic lock: a quality improvement report. Am J Kidney Dis. 2007;50(2): 289-295.

52. Tendas A, Niscola P, Cupelli L, et al. Controversies on antibiotic lock technique duration: experience with a 3-day course for hematological patients. Infect Control Hosp Epidemiol. 2011;32(4):408-410.

53. Sánchez-Muñoz A, Aguado JM, López-Martín A, et al. Usefulness of antibiotic-lock technique in management of oncology patients with uncomplicated bacteremia related to tunneled catheters. Eur J Clin Microbiol Infect Dis. 2005;24(4):291-293.

54. Mermel LA. Prevention of intravascular catheter-related infections. Ann Intern Med. 2000;132(5):391-402.

55. Marschall J, Mermel LA, Classen D, et al. Strategies to prevent central line-associated bloodstream infections in acute care hospitals. Infect Control Hosp Epidemiol. 2008;29 Suppl 1:S22-S30.

56. O'Grady NP, Alexander M, Burns LA, et al; Healthcare Infection Control Practices Advisory Committee. Guidelines for the prevention of intravascular catheter-related infections. Am J Infect Control. 2011; 39(4 Suppl 1):S1-S34.
57. Polgreen PM, Beekmann SE, Diekema DJ, Sherertz RJ. Wide variability in the use of antimicrobial lock therapy and prophylaxis among infectious diseases consultants. Infect Control Hosp Epidemiol. 2010;31(5): 554-557.

58. McKee R, Dunsmuir R, Whitby M, Garden OJ. Does antibiotic prophylaxis at the time of catheter insertion reduce the incidence of catheter-related sepsis in intravenous nutrition? J Hosp Infect. 1985; 6(4):419-425.

59. Sofroniadou S, Revela I, Smirloglou D, et al. Linezolid versus vancomycin antibiotic lock solution for the prevention of nontunneled catheterrelated blood stream infections in hemodialysis patients: a prospective randomized study. Semin Dial. 2012;25(3):344-350.

60. Goossens GA, Jérôme $M$, Janssens $C$, et al. Comparing normal saline versus diluted heparin to lock non-valved totally implantable venous access devices in cancer patients: a randomised, non-inferiority, open trial. Ann Oncol. 2013;24(7):1892-1899.

61. Pronovost P. Interventions to decrease catheter-related bloodstream infections in the ICU: the Keystone Intensive Care Unit Project. Am J Infect Control. 2008;36(10):S171. e1-e5.

62. Baydoun M, Otrock ZK, Okaily S, et al. Prophylactic administration of doxycycline reduces central venous catheter infections in patients undergoing hematopoietic cell transplantation. Mediterr J Hematol Infect Dis. 2013;5(1):e2013015.

63. Scaife CL, Gross ME, Mone MC, et al. Antibiotic prophylaxis in the placement of totally implanted central venous access ports. Am J Surg. 2010;200(6):719-722; disussion 722-723.

64. Sandoe JA, Kumar B, Stoddart B, et al. Effect of extended perioperative antibiotic prophylaxis on intravascular catheter colonization and infection in cardiothoracic surgery patients. J Antimicrob Chemother. 2003;52(5):877-879.

65. Raad II, Hachem RY, Abi-Said D, et al. A prospective crossover randomized trial of novobiocin and rifampin prophylaxis for the prevention of intravascular catheter infections in cancer patients treated with interleukin-2. Cancer. 1998;82(2):403-411.

66. Vassilomanolakis M, Plataniotis G, Koumakis G, et al. Central venous catheter-related infections after bone marrow transplantation in patients with malignancies: A prospective study with short-course vancomycin prophylaxis. Bone Marrow Transplant. 1995;15(1):77-80.

67. Harms K, Herting E, Kron M, Schiffmann H, Schulz-Ehlbeck H. Randomized, controlled trial of amoxicillin prophylaxis for prevention of catheter-related infections in newborn infants with central venous silicone elastomer catheters. J Pediatr. 1995;127(4): 615-619.

68. Lim SH, Smith MP, Machin SJ, Goldstone AH. Teicoplanin and prophylaxis of hickman catheter insertions. Eur J Surg Suppl. 1992;(567) (567):39-42.

69. Ranson MR, Oppenheim BA, Jackson A, Kamthan AG, Scarffe JH. Double-blind placebo controlled study of vancomycin prophylaxis for central venous catheter insertion in cancer patients. J Hosp Infect. 1990;15(1):95-102.

70. McKee R, Dunsmuir R, Whitby M, Garden OJ. Does antibiotic prophylaxis at the time of catheter insertion reduce the incidence of catheter-related sepsis in intravenous nutrition? J Hosp Infect. 1985;6(4):419-425.

71. John BK, Khan MA, Speerhas R, et al. Ethanol lock therapy in reducing catheter-related bloodstream infections in adult home parenteral nutrition patients: Results of a retrospective study. JPEN J Parenter Enteral Nutr. 2012;36(5):603-610.

72. Slobbe L, Doorduijn JK, Lugtenburg PJ, et al. Prevention of catheterrelated bacteremia with a daily ethanol lock in patients with tunnelled catheters: A randomized, placebo-controlled trial. PLoS One. 2010;5(5):e10840.

73. Kayton ML, Garmey EG, Ishill NM, et al. Preliminary results of a phase I trial of prophylactic ethanol-lock administration to prevent mediport catheter-related bloodstream infections. J Pediatr Surg. 2010;45(10):1961-1966. 
74 Osma S, Kahveci SF, Kaya FN, et al. Efficacy of antiseptic-impregnated catheters on catheter colonization and catheter-related bloodstream infections in patients in an intensive care unit. $J$ Hosp Infect. 2006;62(2):156-162.

75. Sheng WH, Ko WJ, Wang JT, Chang SC, Hsueh PR, Luh KT. Evaluation of antiseptic-impregnated central venous catheters for prevention of catheter-related infection in intensive care unit patients. Diagn Microbiol Infect Dis. 2000;38(1):1-5.

76. Hanna H, Afif C, Alakech B, et al. Central venous catheter-related bacteremia due to gram-negative bacilli: Significance of catheter removal in preventing relapse. Infect Control Hosp Epidemiol. 2004;25(8):646-649.

77. Hannan M, Juste RN, Umasanker S, et al. Antiseptic-bonded central venous catheters and bacterial colonisation. Anaesthesia. 1999;54(9):868-872.

78. Darouiche RO, Raad II, Heard SO, et al. A comparison of two antimicrobial-impregnated central venous catheters. catheter study group. $N$ Engl J Med. 1999;340(1):1-8.

79. Collin GR. Decreasing catheter colonization through the use of an antiseptic-impregnated catheter: A continuous quality improvement project. Chest. 1999;115(6):1632-1640.
80. Logghe C, Van Ossel C, D'Hoore W, Ezzedine H, Wauters G, Haxhe JJ. Evaluation of chlorhexidine and silver-sulfadiazine impregnated central venous catheters for the prevention of bloodstream infection in leukaemic patients: A randomized controlled trial. J Hosp Infect. 1997;37(2):145-156.

81. Maki DG, Stolz SM, Wheeler S, Mermel LA. Prevention of central venous catheter-related bloodstream infection by use of an antisepticimpregnated catheter. A randomized, controlled trial. Ann Intern Med. 1997; 127(4):257-266.

82. Raad I, Darouiche R, Dupuis J, et al. Central venous catheters coated with minocycline and rifampin for the prevention of catheter-related colonization and bloodstream infections. A randomized, double-blind trial. the texas medical center catheter study group. Ann Intern Med. 1997; 127(4):267-274

83. Bach A, Schmidt H, Bottiger B, et al. Retention of antibacterial activity and bacterial colonization of antiseptic-bonded central venous catheters J Antimicrob Chemother. 1996;37(2):315-322.

84. Bach A, Darby D, Bottiger B, Bohrer H, Motsch J, Martin E. Retention of the antibiotic teicoplanin on a hydromer-coated central venous catheter to prevent bacterial colonization in postoperative surgical patients Intensive Care Med. 1996;22(10):1066-1069
Infection and Drug Resistance

\section{Publish your work in this journal}

Infection and Drug Resistance is an international, peer-reviewed openaccess journal that focuses on the optimal treatment of infection (bacterial, fungal and viral) and the development and institution of preventive strategies to minimize the development and spread of resistance. The journal is specifically concerned with the epidemiology of antibiotic

\section{Dovepress}

resistance and the mechanisms of resistance development and diffusion in both hospitals and the community. The manuscript management system is completely online and includes a very quick and fair peerreview system, which is all easy to use. Visit http://www.dovepress.com/ testimonials.php to read real quotes from published authors. 